\section{(C) OPEN ACCESS}

\title{
LeHeR, a simple novel approach for difficult airway in non-trauma patients
}

\author{
Nur Hafiza Yezid, ${ }^{1}$ Khadijah Poh, ${ }^{2}$ Julina Md Noor, ${ }^{3}$ Afifi Arshad ${ }^{4}$
}

\begin{abstract}
${ }^{1}$ Emergency and Trauma, Hospital Jitra, Kedah, Malaysia ${ }^{2}$ Emergency and Trauma, University of Malaya, Kuala Lumpur, Malaysia

${ }^{3}$ Emergency Medicine, Universiti Teknologi MARA, Shah Alam, Malaysia

${ }^{4}$ Anaesthesiology, Hospital Sultanah Bahiyah, Alor Setar, Malaysia
\end{abstract}

Correspondence to Dr Nur Hafiza Yezid, drnurhafizayezid@yahoo.com

Accepted 24 July 2019
Check for updates

(c) BMJ Publishing Group Limited 2019. Re-use permitted under CC BY-NC. No commercial re-use. See rights and permissions. Published by BMJ.

To cite: Yezid $\mathrm{NH}$, Poh $\mathrm{K}$ Md Noor J, et al. BMJ Case Rep 2019;12:e230201. doi:10.1136/bcr-2019230201

\section{SUMMARY}

Managing the difficult airway presents a great challenge to anaesthesiologists and emergency physicians. Although there are many methods and scoring systems available to predict and anticipate difficult airway, the dictum in emergency airway is to always expect the unexpected. We have encountered a novel simple method of improving laryngoscopic view in difficult airway. We report four cases of difficult airway encountered in our district hospital from November 2017 to December 2018, in which intubation was performed using a simple manoeuvre called supine left head rotation (LeHeR). In all these cases, LeHeR manoeuvre has proven to be successful after more than a single attempt at intubation using various methods. The manoeuvre improves drastically the laryngoscopic view of Cormack-Lehane from 3B and 4 to 1 and 2 .

\section{BACKGROUND}

Managing difficult airway in remote hospital with limited resources of advanced airway possess real challenge. ${ }^{1}$ Difficult airway is defined as a clinical situation in which a conventionally trained anaesthesiologist experiences difficulty with face mask ventilation of the upper airway, difficulty with tracheal intubation or both. The incidence ranges from $0.4 \%$ to $8.5 \%$ in anaesthesia, and much higher at $2 \%$ to $14.8 \%$ in emergency medicine. ${ }^{23}$ Patients who are difficult to intubate are at higher risk for airway related complications for example aspiration, oesophageal intubation or oropharyngeal trauma. Failed intubation also might cause prolonged hypoxia thus increasing morbidity and mortality. Although there are many methods and scoring systems available to predict and anticipate difficult airway, ${ }^{4}$ the dictum in emergency airway is to always expect the unexpected. We report four cases of difficult airway encountered in our district hospital from November 2017 to December 2018, in which intubation was performed using simple manoeuvre called supine with left head rotation (LeHeR). In all these cases, LeHeR manoeuvre has proven to be successful after more than a single attempt at intubation using various methods.

In an unconscious patient, the muscles of the tongue are flaccid and due to gravity, the tongue tends to fell backward thus obstructing the airway. In supine LeHeR manoeuvre, the exact same issues of flaccid tongue and gravity are used to our benefit wherein the position brings the tongue to the left and gravity pull helps to make the tongue fall backwards but to the left of the patient's head hence improve the laryngoscopic view.

There are four steps for the manoeuvre;

Step 1: The patient is placed on a normal supine with head positioned in simple neck extension.

Step 2: The head is then rotated to the left side to at least 45 degree.

Step 3: The laryngoscope blade is introduced from the centre.

Step 4: An alternative approach is to insert the laryngoscope from the right molar and slide the tongue to the left. The intubation is continued as usual from then on.

Figure 1 shows the method for LeHeR manoeuvre. The neck is rotated to the left due to the fact that the oesophagus lies left and posterior to the trachea. Hypothetically when the patient's head is turned to the left, the oesophagus will be compressed by the cricoid cartilage which moves anteriorly in relation to the oesophagus. This not only improves laryngoscopic view but also reduces the risk of aspiration. This movement of the cricoid cartilage and oesophagus can be seen in the airway ultrasound of a patient (figure 2), taken on a supine position with neck extension (figure $2 a$ ), midway between supine and left rotation (figure $2 b$ ) and when patient's neck is rotated to the left (figure 2c). This real-time airway ultrasound illustrates the movement of the cricoid cartilage in relation to the oesophagus. As the cricoid cartilage moves anteriorly, it displaces the oesophagus more posteriorly.

\section{CASE PRESENTATION}

\section{Case 1}

A 3-year-old girl with underlying gross hydrocephalus was brought into emergency department (ED) by her caretaker in respiratory distress. She was diagnosed to have aspiration pneumonia, with oxygen saturations of $80 \%$ despite being on high flow $(15 \mathrm{~L} / \mathrm{min})$ oxygen via non-rebreather mask. The junior doctor (less than 2 years' experience) decided to intubate the patient in view of poor ventilatory effort and low oxygen saturation. However, due to her large head, the neck tend to be in flexed position and the doctor had difficulty viewing the glottis despite cricoid pressure and backwards-upwards-right position (BURP) manoeuvre. Intubation was attempted with various manoeuvres (ramp, sniffing position and hyperextension) and were unsuccessful after three attempts even after a more senior doctor attended. The emergency physician was then called and despite 

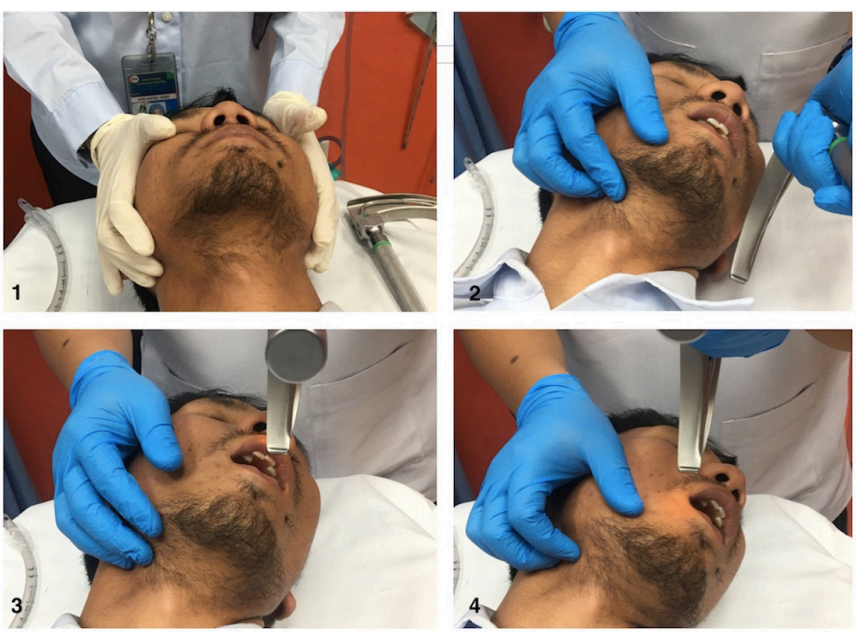

Figure 1 Steps of supine LeHeR (left head rotation) manoeuvre. Step 1 : The patient is placed on a normal supine with head positioned in simple neck extension. Step 2: The head is then rotated to the left side to at least 45 degree. Step 3: The laryngoscope blade is introduced from the centre. Step 4: An alternative approach is to insert the laryngoscope from the right molar and slide the tongue to the left. The intubation is continued as usual from then on.

placing the patient a ramp and sniffing position, the glottis was still not visible (Cormack-Lehane 4). The patient's large head was then turned to her left side (LeHeR - left head rotation), which improved the view to Cormack-Lehane $2 \mathrm{~A}$, resulting in successful intubation by the emergency physician.

\section{Case 2}

A 9-month-old girl presented to our ED with status epilepticus secondary to meningitis. The child has been fitting for more than $45 \mathrm{~min}$ and is cyanosed. Intubation was hindered by a floppy epiglottis (Cormack-Lehane $3 \mathrm{~A}$ ) and she desaturated to $57 \%$ despite on bag-valve-mask ventilation. After two failed attempts to intubate in normal supine position by the junior

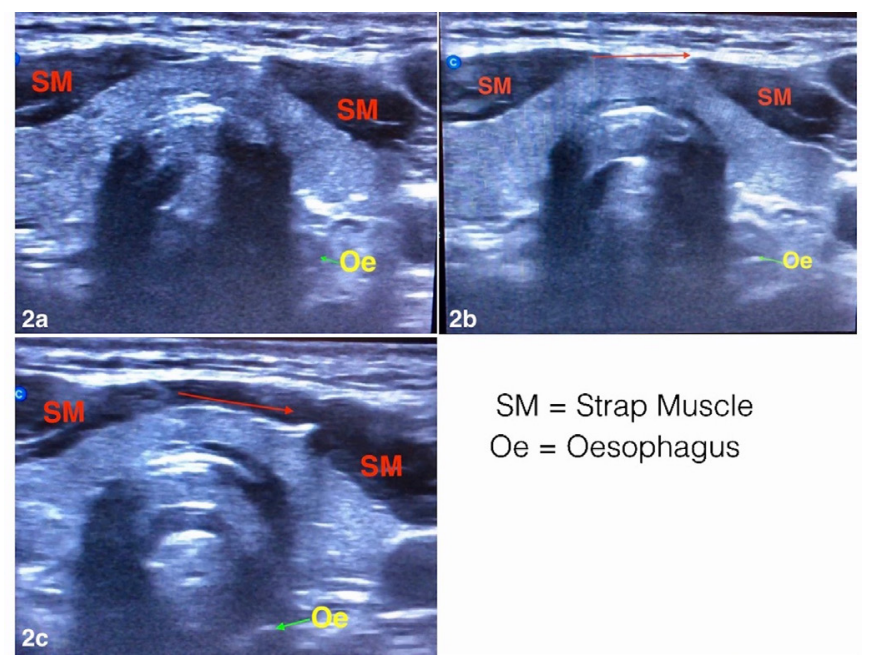

Figure 2 Movement of the cricoid cartilage and oesophagus can be seen in the airway ultrasound of a patient. (2a) Airway ultrasound at level of first tracheal ring in normal supine with simple head extension. (2b) Airway ultrasound at level of first tracheal ring at 20 degree left head rotation. (2c) Airway ultrasound at level of first tracheal ring at 45 degree left head rotation. doctor, the decision to apply LeHeR manoeuvre was made by the same doctor, the ventilation became much easier and the oxygen saturation improved. The laryngoscopic view improved to Cormack-Lehane 1 and she was then successfully intubated, while still in the LeHeR position.

\section{Case 3}

A 25 -year-old man brought from drug rehabilitation centre in cardiac arrest. The chest rise was poor during bag-valve-mask ventilation and extraglottic airway. Attempts to intubate the patient during chest compression by senior medical officer (experience more than 2 years) revealed Cormack-Lehane $3 \mathrm{~B}$. Due to the longer time it takes to intubate during cardiac compression (two attempts by same person), we applied the LeHeR manoeuvre to ventilate and intubate the patient. The vocal cord was clearly visualised with Cormack-Lehane 1 , and intubation was easy during chest compression (intubated by the same person who failed to intubate on the first two attempts). However, patient did not survive.

\section{Case 4}

A 33-year-old morbidly obese man (approximately $200 \mathrm{~kg}$ ) arrived at the emergency department in acute confusional state with septicaemic shock secondary to severe pneumonia. There was difficulty to intubate this man despite multiple attempts to intubate by three junior doctors and one paramedic (with 5 years experience in emergency department) using various manoeuvres and with the aid of a bougie. The initial laryngoscopic view showed a Cormack-Lehane 3B. The oxygenation was maintained at $80 \%$ throughout the $45 \mathrm{~min}$ attempt by allowing spontaneous breathing augmented by bag-valve-mask. Surgical airway was not considered as the patient was morbidly obese and the anterior neck anatomy was covered on the laryngeal handshake. After $45 \mathrm{~min}$, the emergency physician was called in and supine LeHeR was performed. The patient was then intubated with ease by the same junior doctor as the Cormack-Lehane score improved to 1 .

Outcome and follow-up

- Patient in case 1 , discharged well after 2 weeks.

- Patient in case 2, discharged well after 1 week without neurological sequelae. Patient also visited Emergency Department Hospital Jitra in early March 2019 with her parents for simple viral croup.

- Patient case 3 was brought in dead and could not be revived after resuscitation.

- Patient case 4, succumbed to his death after 2 days in ICU due to sepsis.

\section{DISCUSSION}

Patients who are difficult to intubate are at higher risk for airway related complications for example, aspiration, oesophageal intubation and oropharyngeal trauma. Failed intubation may also lead to prolonged hypoxia thus increasing morbidity and mortality. ${ }^{5}$

Data from the UK shows that the majority of complications in airway management occur in the emergency department and the intensive care unit. ${ }^{6}$ In resource limited setting, especially in remote/district hospital, managing difficult airway poses real challenges to the junior doctors.

To improve laryngoscopy view, few manoeuvres have been proposed such as BURP, cricoid pressure and external laryngeal manipulations. BURP was introduced by Knill in 1993, and later 
validated by Takata. However recent studies by Snider et al in 2005 showed that BURP manoeuvre may distort the laryngeal view, and the view may worsen if cricoid pressure is applied. ${ }^{78}$ Furthermore, cricoid pressure or external laryngeal manipulation, must be done with certain amount of pressure. Too much of pressure might worsen the view while not enough pressure renders it ineffective. In addition to that, it requires at least two persons; one to intubate and one to manipulate the airway.

Many intubation positions for difficult airway has been described in the literature, and the most widely practised in anaesthesia and emergency department are simple neck extension and sniffing position. There are also suggestions to intubate patient in sniffing position, however randomised study by Adnet et al in 2001 comparing the sniffing position with simple head extension to improve laryngoscopy view shows no difference in the outcome. ${ }^{9}$

Our district hospital does not have paediatricians or anaesthetists available. Advanced airway resources are also limited in which the only bougie available to aid difficult airway. Before emergency physician placed in district hospital, most of the difficult airway patient that they encounter was send immediately to tertiary hospital with extraglottic airway in place, which does not protect patient from aspiration and some patients with acute respiratory distress syndrome did not make it to reach the main hospital. Therefore, we have developed this new non-invasive technique to assist us in tackling difficult airway in non-trauma patients.

In Case 1, the gross hydrocephalus already predicts difficult intubation due to the size of the head. Without placing a ramp, the airway will be in flexed position, making it difficult to ventilate and intubate. A case report by Vagyannavar et al in 2017, on difficult airway in a child with gross hydrocephalus discusses about the Cormack-Lehane 3 and floppy epiglottis and successful intubation after third attempt by senior anaesthesiologist after ramp up. ${ }^{10}$ However, in our patient, intubation was unsuccessful despite placement of a ramp. We therefore proceeded with the LeHeR manoeuvre.

The mechanism of increasing the airway space and improving visualisation of the glottis in LeHeR is thought to be gravitational, and it is also possible that the neck rotation increases muscle tension and lifts up the glottis. This can be explained and found in MRI study by Ono et al. They performed a study comparing airway in supine position, supine with head rotation and in lateral recumbent and found out that in their two-dimensional MRI study, in supine position, the anterior portion of the retropalatal airway was compromised by the soft palate and the overall shape of the upper airway calibre was moved downwards. ${ }^{11}$ While in the supine with head rotation, the cross-sectional area of the upper airway seemed to be increased in the upper and lower retroglossal regions compared with those in the supine anatomical position. In addition, the overall shape of the upper airway in supine with head rotation calibre was moved upwards.

In the same study, they made three-dimensional MRI reconstructions of the airway in different head positions, and they found out that there was a significant increase in volume in the retroglossal region when the subject rotated his head in the supine position. They concluded that, head rotation induced a marked increase in the upper airway diameter in addition to an increase in the cross-sectional area in the retroglossal region. ${ }^{11} 12$

This can be seen in figure 3 of Case 3 where in the normal supine view, the trachea cannot be visualised and even with external laryngeal manipulation (Cormack-Lehane 2B). While in LeHeR position, the trachea can be visualised with ease, and the
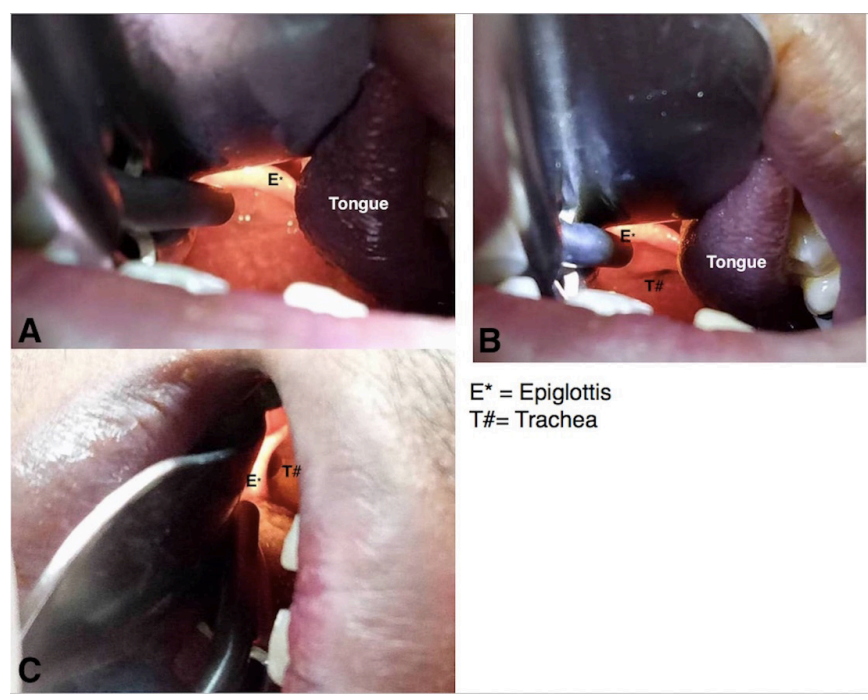

$\mathrm{E}^{\star}=$ Epiglottis

T\#= Trachea

Figure 3 Direct laryngoscopy view of patient in case 3. (A) Normal supine with simple neck extension. (B) Supine with neck extension and external laryngeal manipulation. (C) Supine LeHeR (left head rotation) without external laryngeal manipulation.

flaccid tongue was pulled down and to the left of patient's head by gravity.

The same supine LeHeR manoeuvre was applied on patient in Case 4, where failed multiple attempts of intubation in normal supine by three different doctors. In figure 4 , the large and floppy aryepiglottic fold was mistaken as epiglottis hence resulted in oesophageal intubation. While in supine LeHeR position, the trachea can clearly be visualised thus can be intubated by the same doctor that initially failed to intubate in normal supine position initially.

In 2010, Greenland et al developed a new airway concept called the 'two-curve theory' to understand the impact of the head and neck positioning has, not only on tracheal intubation using laryngoscopes blades, but for all airway devices. In this two-curve theory, Greenland named the primary curve as oropharyngeal curve and secondary curve as pharyngo-glotto-tracheal curve to better explain the three axis alignment theory. ${ }^{13-15} \mathrm{We}$ concur and think that the LeHeR position improves the primary curve by shortening the curve. However more studies should be done to confirm it.
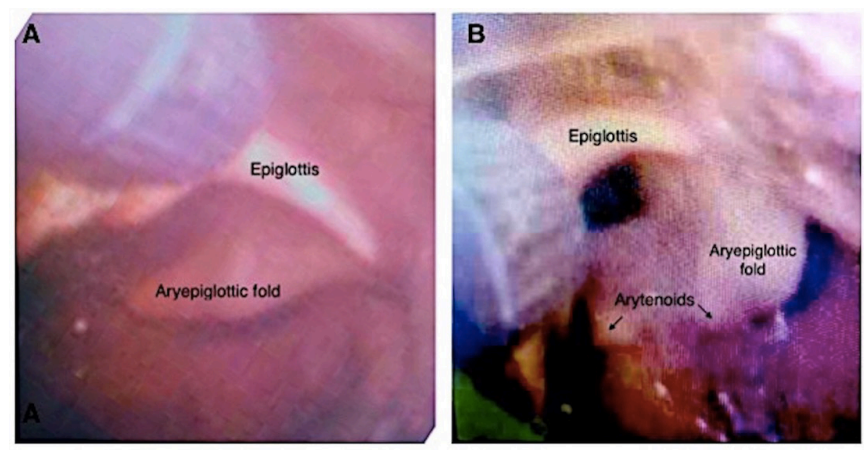

Figure 4 Laryngoscopy view of patient in case 4. (A) View taken in normal supine without neck extension shows Cormack-Lehane 3B. (B) View taken in supine LeHeR (left head rotation) of the same patient shows Cormack-Lehane 1. 
Despite supine LeHeR gives optimal laryngoscopy view, the manoeuvre is limited to non-trauma patient and to those without spinal rigidity or stiff neck.

\section{Learning points}

- Simple manoeuvre (supine LeHeR) can markedly improve the direct laryngoscopy view with improvement of CormackLehane at least by 1 grade.

- Backwards-upwards-right position manoeuvre, simple neck extension with external laryngeal manipulation might not be helpful in improving view in certain patients.

- Gravity, and muscle tension might play a role in this supine LeHeR (left head rotation) manoeuvre. However further study is needed to prove it.

- In managing difficult airway in non-trauma patient, this simple and non-invasive manoeuvre can be attempted before proceeding to another surgical airway technique.

Contributors NHY developed the manoeuvre and performed the technique, wrote the manuscript in consultation and input of all authors. AA provided input from anaesthesia point of view, JMN provided input from ultrasound point of view. KP and JMN involved in final editing of the manuscript. All authors contributed to refine the study and approved the final manuscript.

Funding The authors have not declared a specific grant for this research from any funding agency in the public, commercial or not-for-profit sectors.

Competing interests None declared.

Patient consent for publication Parental/guardian consent obtained.

Provenance and peer review Not commissioned; externally peer reviewed.

Open access This is an open access article distributed in accordance with the Creative Commons Attribution Non Commercial (CC BY-NC 4.0) license, which permits others to distribute, remix, adapt, build upon this work non-commercially, and license their derivative works on different terms, provided the original work is properly cited and the use is non-commercial. See: http://creativecommons.org/ licenses/by-nc/4.0/

\section{REFERENCES}

1 Apfelbaum JL, Hagberg CA, Caplan RA, et al. Practice guidelines for management of the difficult airway. Anesthesiology 2013;118:251-70.

2. Burkle $\mathrm{CM}$, Walsh MT, Harrison $\mathrm{BA}$, et al. Airway management after failure to intubate by direct laryngoscopy: outcomes in a large teaching hospital. Can J Anaesth 2005;52:634-40

3 Crosby ET, Cooper RM, Douglas MJ, et al. The unanticipated difficult airway with recommendations for management. Can J Anaesth 1998:45:757-76.

4 Yentis SM. Predicting difficult intubation--worthwhile exercise or pointless ritual? Anaesthesia 2002;57:105-9.

5 Cook TM, MacDougall-Davis SR. Complications and failure of airway management. $\mathrm{Br}$ J Anaesth 2012;109(SUPPL1):i68-i85.

6. Cook TM, Woodall N, Frerk C. Fourth National Audit Project. Major complications of airway management in the UK: results of the Fourth National Audit Project of the Royal College of Anaesthetists and the Difficult Airway Society. Part 1: anaesthesia. $\mathrm{Br}$ J Anaesth 2011:106:617-31.

7 Snider DD, Clarke D, Finucane BT. The "BURP" maneuver worsens the glottic view when applied in combination with cricoid pressure. Can J Anaesth 2005;52:100-4.

8 Salem MR, Heyman HJ, Mahdi M. Facilitation of tracheal intubation by cephalad displacement of the larynx--rediscovered. J Clin Anesth 1994;6:167-8.

9 Lefebure L, Denantes C, Lapostolle F, et al. Randomized study comparing the "Sniffing Position" with simple head extension for laryngoscopic view in elective surgery patients. Anesthesiology 2003;95:836-41.

10 Vagyannavar R, Bharti V, Hashim M. Difficult airway in a case of gross hydrocephalus for shunt surgery. Anesthesia: Essays and Researches 2017;11:1109.

11 Ono T, Otsuka R, Kuroda T, et al. Effects of head and body position on two- and threedimensional configurations of the upper airway. J Dent Res 2000;79:1879-84.

12 Itagaki T, Oto J, Burns SM, et al. The effect of head rotation on efficiency of face mask ventilation in anaesthetised apnoeic adults: A randomised, crossover study. Eur J Anaesthesiol 2017;34:432-40.

13 Adnet F, Borron SW, Lapostolle F, et al. The three axis alignment theory and the "sniffing position": perpetuation of an anatomic myth? Anesthesiology 1999;91:1964-5

14 Greenland K. The ramped position and its relationship to the 2-curve theory. Anesth Analg 2011;113:1524-5.

15 Greenland KB. A proposed model for direct laryngoscopy and tracheal intubation. Anaesthesia 2008;63:156-61.

Copyright 2019 BMJ Publishing Group. All rights reserved. For permission to reuse any of this content visit

https://www.bmj.com/company/products-services/rights-and-licensing/permissions/

BMJ Case Report Fellows may re-use this article for personal use and teaching without any further permission.

Become a Fellow of BMJ Case Reports today and you can:

- Submit as many cases as you like

- Enjoy fast sympathetic peer review and rapid publication of accepted articles

- Access all the published articles

- Re-use any of the published material for personal use and teaching without further permission

Customer Service

If you have any further queries about your subscription, please contact our customer services team on +44 (0) 2071111105 or via email at support@bmj.com.

Visit casereports.bmj.com for more articles like this and to become a Fellow 